\title{
La EDD potrebbe ancora avere un ruolo importante
}

\section{Claudio Ponticelli}

\author{
Ospedale Maggiore, Divisione Nefrologia, Dialisi e Trapianto, Padiglione Croff, Milano
}

$\mathbf{N}$ on sono contrario all'emodialisi domiciliare. Anzi, in diverse circostanze tale terapia può essere considerata il trattamento dialitico di scelta.

Il vero problema per cui l'emodialisi domiciliare è stata pressoché abbandonata è rappresentato dalla carenza di personale infermieristico. Il periodo di addestramento dura diversi mesi. Almeno in molti ospedali del Nord-Italia, non è possibile che un infermiere si dedichi all'addestramento per periodi così lunghi. Tale ostacolo potrebbe forse essere superato con l'intervento di istruttori esterni, forniti dalle industrie di dialisi.

Un secondo problema è costituito dalla scelta del partner. Il partner ideale è il coniuge. Tuttavia, se l'unione familiare viene spesso cementata da questa esperienza, in altri casi si può creare uno stato di conflitto $\mathrm{e}$ di tensione fra i coniugi.

La scelta di fratelli o figli, come partner, è più delicata. In linea di massima sono sfavorevole a tale scelta in quanto impedisce la possibilità di una vita completamente autonoma ai giovani partner. Il genitore è invece un ottimo partner per gli adolescenti o i giovani adulti.

In conclusione, ritengo che l'emodialisi domiciliare potrebbe ancora avere un ruolo importante.

È però necessaria un'impostazione più pragmatica da parte delle autorità sanitarie regionali che dovrebbero cercare soluzioni adeguate all' affollamento dei Centri dialisi e alla carenza di personale.

ponticel@polic.cilea.it 